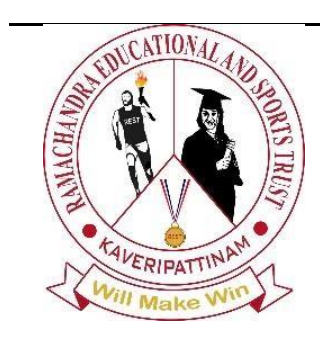

REST Journal on Emerging trends in Modelling and Manufacturing

Vol: 6(2), 2020

REST Publisher

ISSN: 2455-4537

Website: www.restpublisher.com/journals/jemm

\title{
Analysis of Tensile Properties of Hybrid Fiber Reinforced Composite
}

\section{Veda Swaroop, D. Mahesh, B. Naga Sai Phani Kumar, Jenarthnana M P}

School of Mechanical Engineering, Sastra deemed to be university, Thanjavur, India

jenarthanan@mech.sastra.edu

\begin{abstract}
Natural fibers being eco -friendly, renewable and its abundance made it a viable substitute for synthetic fibers. One of the main reasons for using natural fibers is their continuous supply, easy and safe handling, and biodegradable nature. But when compared to synthetic fibers the natural fibers lack in terms of strength and adhesion. To increase the strength and adhesion of natural fibers, they are chemically treated with $5 \% \mathrm{NaOH}$. Hybrid composites contains more than one fiber and the fibers considered need to be in a specific ratio called fiber ratio to obtain better and required properties. Hybrid composites can provide better properties of stiffness, strength and ductility, as well as bending and mechanical properties such as hardness, toughness and fatigue life. The main aim of the present research is to perform the analysis of tensile properties of pineapple leaf-banana fiber reinforced hybrid polypropylene composites using Finite Element Analysis (ANSYS). Pineapple leaf and banana fiber are taken in the ratios of 1:1,3:1,1:3. Tensile properties of the composites are subsequently analyzed. The effective fiber ratio is expected to be obtained among the three fiber ratios.
\end{abstract}

Keywords: Pineapple leaf fiber; Banana fiber; ANSYS; tensile strength; Polypropylene.

\section{Introduction}

Natural fibers are ecofriendly, strong, renewable, cheap and biodegradable. Natural fiber a polymer consists of a polymer matrix reinforced with high strength natural fiber. The properties like low density, low cost and ecological advantages make them better over synthetic composites. These properties of natural fiber make them more attractive than synthetic composites. Hybrid composites can have more than one reinforcing phase and a single matrix phase or single reinforcing phase with multiple matrix phases or multiple reinforcing and multiple matrix phases. Hybrid composites show better properties than binary systems containing one type of fiber dispersed in a matrix. This gives better hybrid composites strength, ductility, bending and membrane related mechanical properties with weight savings and reduced notch sensitivity. The main disadvantages of natural fibers in composites are their poor compatibility between fiber and matrix and the relatively high moisture sorption. Hence chemical treatments are considered in modifying and improving the fiber surface properties. The aim of the project is to develop a new hybrid using eco-friendly banana and pineapple leaf fiber. Effects of chemically treated fibers with different ratios on Tensile properties of pineapple leaf and banana fiber reinforced hybrid polypropylene composite were observed.

\section{1 review of literature:}

1. S.Das, et al. (2018) discussed the variation in mechanical properties between raw and 5\% NaoH treated natural fibers and reported that alkali treated natural fibers showed better results than raw fibers. The effect of pineapple leaf and banana fiber ratio $(1: 1,1: 3,3: 1)$ on its mechanical properties were discussed.

2. L.Uma Devi,et al (1998) discussed the tensile, flexural, and impact behavior of PALF-reinforced polyester composites as a function of fiber loading, fiber length, and fiber surface modification. The tensile strength and Young's modulus of the composites were found to increase with fiber content in accordance with the rule of mixtures.

3.Merlini,et al (2011). have discussed the effect of surface treatment on the chemical properties of banana fiber and reported that treated banana fiber gives higher shear interfacial stress and tensile strength when compared with the untreated fiber.

4. Laban, et al (2001) has studied On the physical and mechanical behavior of banana fiber reinforced polymer composite and noticed that Kraft mashed banana fiber material has better flexural strength. The tensile strength is detected maximum at $30 \mathrm{~mm}$ fiber length whereas the impact strength is noticed maximum at $40 \mathrm{~mm}$ length of fiber. Consolidation of $40 \%$ untreated banana fibers gives $20 \%$ rise in impact strength.

5. Oluyemi Ojo DARAMOLA, et al. discussed the ultimate tensile strength and the young's modulus of elasticity of 
PALF/Polyester composites increase linearly with increase in the fiber weight fraction. The optimum flexural strength and flexural modulus were obtained at $20 \mathrm{wt} . \%$ PALF while the optimum hardness value was obtained at $30 \mathrm{wt} \%$ PALF.

6. K. Senthilkumar, et al (2018). Investigated on effect of PALF loading in polyester composites on mechanical, morphological, free vibrational and damping properties. And he revealed that the tensile, compressive strength and flexural properties considerably increased with increasing PALF loading according to the rule of mixtures.

\section{Materials}

2.1 Pineapple Fibre: PALF has high specific strength and stiffness and it is hydrophilic in nature due to high cellulose content. Extraction of fibers from pineapple leaf fiber is carried out by mechanical method and retting method. Fresh leaves yield about 2 to $3 \%$ of fibers. Fibrous cell of PALF consists of a vascular bundle system in the form of bunches which is obtained after mechanical removal of the entire upper layer after harvesting. PALF is composed of many chemical constituents and is multicellular lignocellulose fiber containing polysaccharides, lignin in a major amount. Fiber is a collection of thin and small multicellular fibers which appears like a thread. These cells are tightly joined with the help of pectin. PALF constitutes cellulose (70-82\%) and arrangement of fibers resembles cotton. Pineapple leaf fiber is an important natural fiber with high specific strength, flexural, torsional rigidity and rigidity. Considering these exclusive properties of PALF, industries can use it as an alternative raw material in the prospect of reinforcing composite matrices

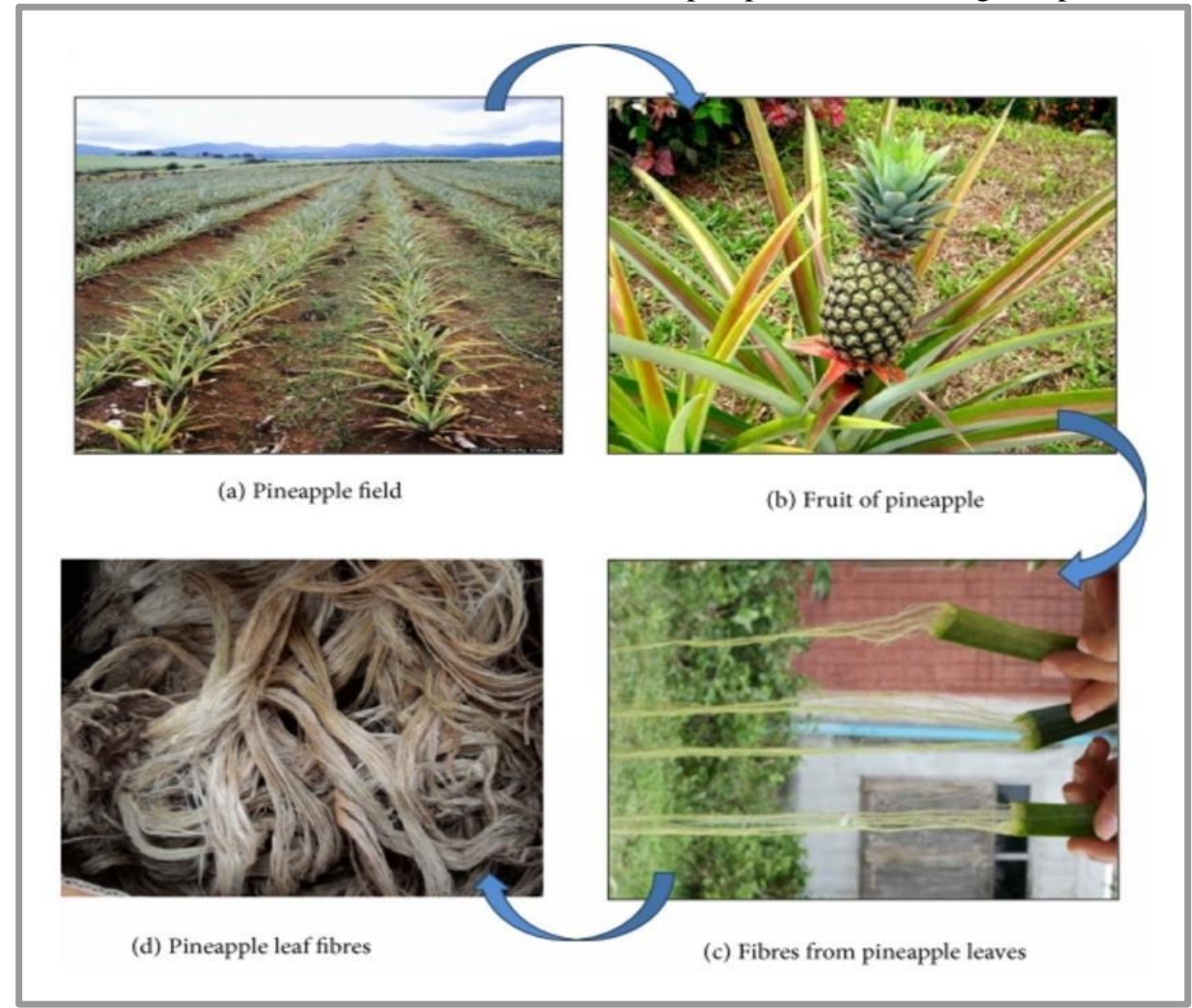

Fig. 1.1 Pineapple Leaf Fiber

2.2 Banana Fibre: Banana is one of the most well-known and useful plants in the world where each part of the plane serves a useful purpose. It is a lingo-cellulosic fiber, which obtained from the pseudo stem of banana plant. Banana fiber is extracted by retting and degumming method. Banana fiber is a best fiber with relatively good mechanical properties and has good specific strength properties comparable to those of conventional material, like glass fiber. The pseudo-stem is a cylindrical, clustered aggregation of leaf stalk bases. Banana fibers have smaller elongation, highly strength, light weight, fire resistance quality, strong moisture absorption quality, great potentialities and biodegradability 

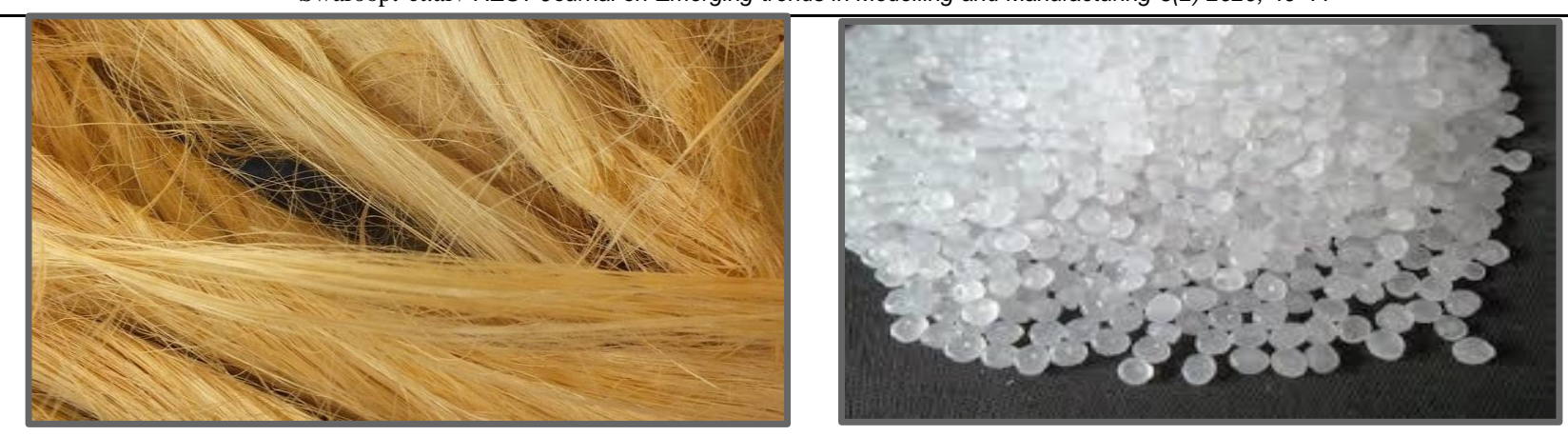

Fig. 1.2 Banana Fiber; Fig.1.3 Polypropylene

2.3 Polypropylene: Polypropylene is used as a resin in the hybrid composite which contributes strength, chemical resistance and durability to the composite. Melting Point of Polypropylene ranges between 160 - $170 \mathrm{C}$ and varies for homo and copolymer. The specific gravity varies between $0.90-0.91 \mathrm{~g} / \mathrm{cm} 3$.

2.4 Naoh Treatment: Sodium hydroxide $(\mathrm{NaOH})$, also known as caustic soda or lye, is a highly versatile substance used in a variety of manufacturing processes. It is a white solid ionic compound consisting of sodium cations Na+ and hydroxide ions $\mathrm{OH}-$. The alkaline treatment is a chemical treatment in which the natural fibers are immersed in a known concentration of aqueous sodium hydroxide ( $\mathrm{NaO}$ ) for a given temperature and a period of time. The alkali treatment breaks hydrogen bonds between the hydroxyl groups $(-\mathrm{OH})$ of the cellulose, hemicellulose and lignin and leads to defibrillation, the breakdown of the fiber bundle into smaller fibers. This change increases the effective surface area.

\section{Methodology}

3.1. Ansys Introduction: Mechanical finite element analysis software is employed to simulate computer models of structures, electronics, or machine components for analyzing strength, toughness, Hardness, elasticity, temperature distribution, electromagnetic properties, fluid flow, and other attributes. The software is used to create a virtual model of the hybrid fiber composite and ran a simulation for tensile strength of the composites using different loads for both treated and untreated fibers.

3.2. Model Creation: In ANSYS, ACP Pre module is created and Engineering data is updated with values such as density, young's modulus of 5\% NaOH treated banana and pineapple leaf fiber. Then geometry of the model is created with 400 sq, mm surface area. Then composite setup has been done and connected with static structure and ACP Post. In a static structure, a geometric model is taken and material has been assigned in 1:3,1:1,3:1(pineapple to banana). Force of $5 \mathrm{~N}$ is applied for all models and respective tensile strengths have been recorded.

Table 3.1 Engineering Data

\begin{tabular}{|l|c|c|c|}
\hline Material & Density(g/cc) & Young's Modulus(MPa) & Poisson's Ratio \\
\hline Banana fiber & 1.4 & 1350 & 0.29 \\
\hline Pineapple leaf & 1.11 & 1500 & 0.45 \\
\hline Polypropylene & 0.855 & 1325 & 0.43 \\
\hline
\end{tabular}

Note: All the values for banana fiber and PALF fiber are the values when they are treated with $5 \% \mathrm{NaOH}$.

\section{Results And Discussion}

4.1. ANSYS model for composite with fiber ratio 1:3(PALF: Banana): 


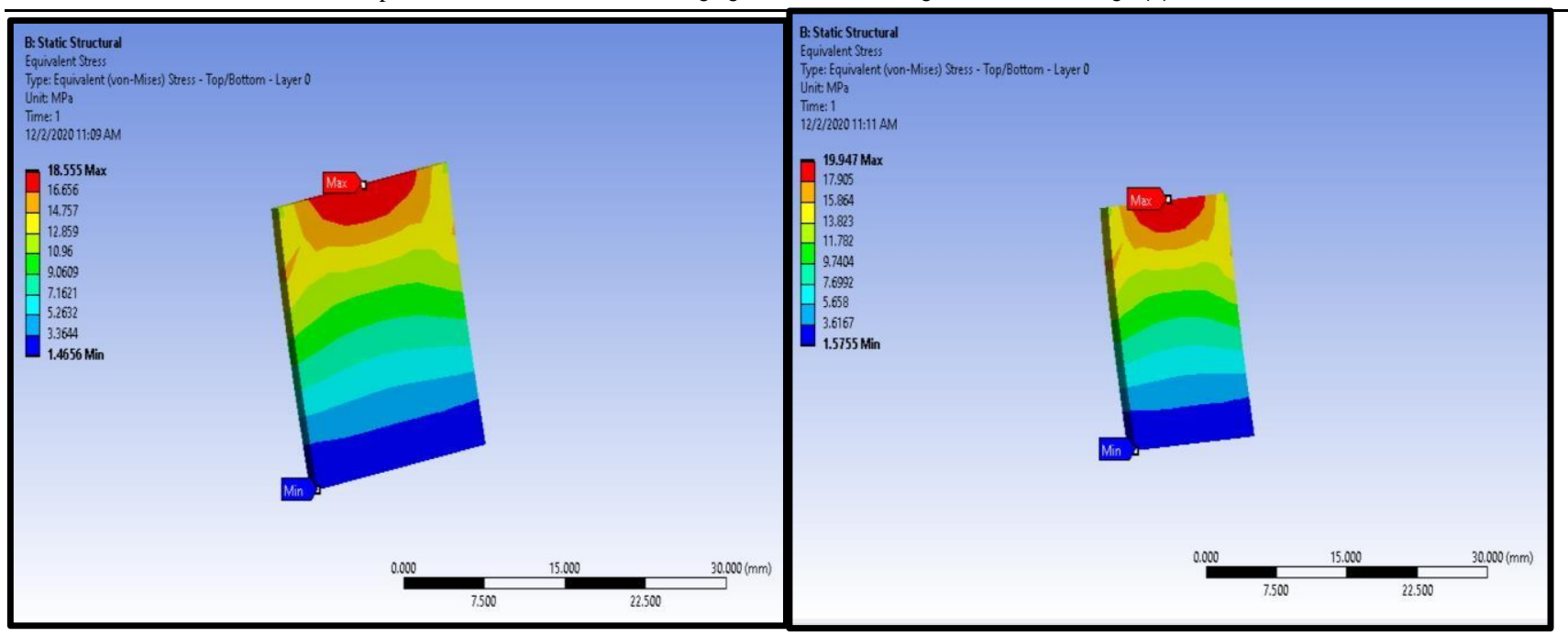

Fig.4.1 Model with fiber ratio 1:3 (PALF: Banana); Fig.4.2 Model with fiber ratio 1:1 (PALF: Banana)

From the model fig.4.1, one edge is made fixed and a load of $5 \mathrm{~N}$ is applied on the opposite edge. From the above model it is evident that the maximum tensile strength and minimum tensile strengths are $19.95 \mathrm{MPa}$ and 1.58 MPa 1:3ratio (PALF: banana).

\subsection{ANSYS model for composite with fiber ratio 1:1(PALF: Banana):}

From the model fig.4.2, one edge is made fixed and a load of $5 \mathrm{~N}$ is applied on the opposite edge. From the above model it is evident that the maximum tensile strength and minimum tensile strengths are $18.56 \mathrm{MPa}$ and $1.47 \mathrm{MPa}$ for $1: 1$ ratio (PALF: banana).

\subsection{ANSYS model for composite with fiber ratio 3:1(PALF: Banana):}

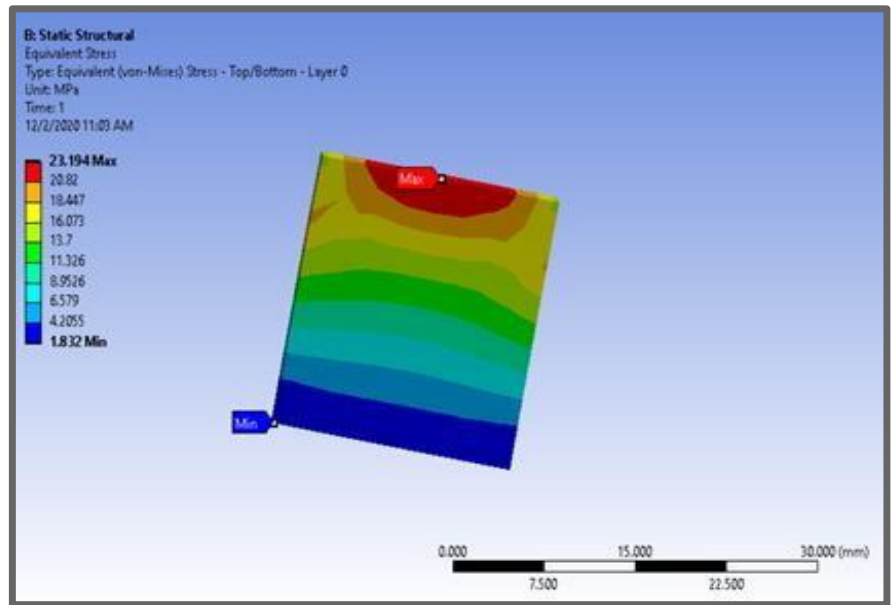

tensile strength(MPa) vs. fiber ratio

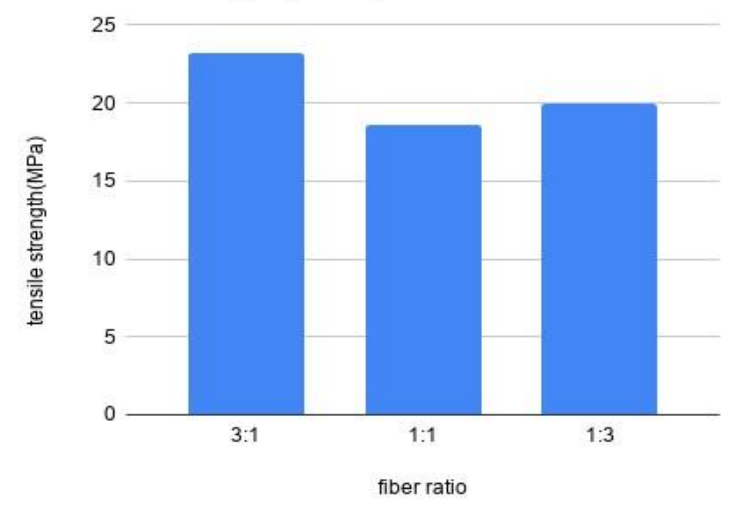

Fig.4.3 Model with fiber ratio 3:1(PALF: Banana); Fig.4.4 Graphical Representation of fiber ratios

From the model Fig.4.3, one edge is made fixed and a load of $5 \mathrm{~N}$ is applied on the opposite edge. From the above model it is evident that the maximum tensile strength and minimum tensile strengths are 23.2 MPa and 1.83MPa for 3:1 ratio (PALF: banana). This ratio of 3:1 exhibited better tensile properties among the three different fiber ratios.

\subsection{Interpretation}

Table 4.1 Interpretation table

\begin{tabular}{|c|c|c|c|}
\hline SI no & Ratio (palf : Banana) & Max Tensile strength (MPa) & Min Tensile strength (MPa) \\
\hline $\mathbf{1}$ & $3: 1$ & 23.2 & 1.83 \\
\hline $\mathbf{2}$ & $1: 1$ & 18.56 & 1.47 \\
\hline $\mathbf{3}$ & $1: 3$ & 19.95 & 1.58 \\
\hline
\end{tabular}


From the above analysis it is evident that the composite with the ratio 3:1 (PALF: banana fiber) showed higher max tensile strength of 23.2MPa among different compositions.

\subsection{Discussion}

Treated fibers (i.e. fibers treated with $5 \% \mathrm{NaOH}$ ) are considered because the alkaline treatment modifies the surface of fibers by removing certain rates of lignin, wax and oils covering the external surface of natural fibers. The removal of certain quantities of lignin wax and hemicellulose improves the matrix-fiber interface which ensures proper adhesion between the matrix and natural fibers. Alkaline treatment increases the density of fiber by removing non -cellulosic components. After alkaline treatment the fibers turn to yellow color and the intensity of color varies based on the $\mathrm{NaOH}$ concentration. During the alkaline treatment, the fibers are separated from each other which simultaneously increases the effective surface area available for wetting by the resin(polypropylene). The cellulose is the strongest and has more stiffness components. Hence the alkali treatment improves the rate of crystalline cellulose content. Thus the alkaline treatment of natural fibers enhances the mechanical properties of composite by improving the charge transfer between the matrix and fiber. Three models with pineapple to banana fiber ratio of $3: 1,1: 3,1: 1$ combination are created separately. For all models the same conditions are maintained such as fixed support and force applied $(5 \mathrm{~N})$. The results have been collected and interpreted. Thus composite with the ratio 3:1(PALF: banana) can be used in the applications.

\section{Conclusion}

In the present project, the effect of pineapple leaf and the banana fiber ratio on tensile properties of pineapple leaf and banana fiber reinforced hybrid polypropylene composites are observed. Composite models were prepared with pineapple leaf and banana fiber in 3:1, 1:1 and 1:3 ratios. Tensile properties were higher for 3:1 fiber ratio composites compared to the other fiber ratio. Further analysis regarding flexural properties, hardness and surface morphology need to be conducted to obtain the best of these three fiber ratios. When tensile properties are considered, the composite model with fiber ratio of 3:1(PALF: Banana) showed better values of around 23.2 MPa.

\section{References}

[1].S. Das, M. Rahman and M. Hasan., Physico-Mechanical Properties of Pineapple Leaf and Banana Fiber Reinforced Hybrid Polypropylene Composites., Department of Materials and Metallurgical Engineering, Bangladesh University of Engineering and Technology(2018).

[2].M H Zin, K Abdan, N Mazlan, E S Zainudin and K E Liew.The effects of alkali treatment on the mechanical and chemical properties of pineapple leaf fibres (PALF) and adhesion to epoxy resin Institute of Tropical Forestry and Forest Products, Universiti Putra Malaysia, 43400 UPM Serdang, Selangor, Malaysia.

[3].Julio César Mejía Osorio,Rodolfo Rodríguez Baracaldo, Jhon Jairo Olaya Florez.The influence of alkali treatment on banana fibre mechanical properties. Departamento de Ingeniería Mecánica y Mecatrónica, Universidad Nacional de Colombia.December 2010.

[4].Jenarthanan, M. P., S. Ramesh Kumar, G. Venkatesh, and S. Nishanthan. "Analysis of leaf spring using Carbon/Glass Epoxy and EN45 using ANSYS: A comparison." Materials Today: Proceedings 5, no. 6 (2018): 14512-14519.

[5].L. Uma Devi ,S. S. Bhagawan ,Sabu Thomas., Mechanical properties of pineapple leaf fiber-reinforced polyester composites(1998).

[6].K.Senthilkumar,N.Saba,M.Chandrasekar,M.Jawaid,N.Rajini,Othman,Y.Alothman, Suchart Seingchin Evaluation of mechanical and free vibration properties of the pineapple leaf fibre reinforced polyester composites(2018).

[7].Merlini C., Soldi V., Barra G. M. O., Influence of Fiber Surface Treatment and Length on Physico-Chemical Properties of Short Random Banana Fiber-Reinforced Castor Oil Polyurethane Composites, Polymer Testing, 30 (2011), pp. 833-840. [8].Jenarthanan, M. P., S. Ramesh Kumar, and R. Jeyapaul. "Modelling of machining force in end milling of GFRP composites using MRA and ANN." Australian Journal of Mechanical Engineering 14, no. 2 (2016): 104-114.

[9].Laban B. G., Corbiere-Nicollier T., Leterrier Y., Lundquist L., Manson J. -A. E., Jolliet O., Life Cycle Assessment of Biofibers Replacing Glass Fibers as Reinforcement in plastics, Resources Conservation and Recycling, 33(2001), pp. 267287. [10].Oluyemi Ojo DARAMOLA, Adeolu Adesoji ADEDIRAN 2,Benjamin Omotayo ADEWUYI 1, and Olamigoke ADEWOLE 1 Mechanical properties and water absorption behaviour of treated pineapple leaf fibre reinforced polyester matrix .

[11].Ans Al Rashid, Muhammad Yasir Khalid, Ramsha Imran, Umair Ali, and Muammer KocUtilization of Banana FiberReinforced Hybrid Composites in the Sports Industry 2020.

[12].Maleque M. A., Belal F. Y., Sapuan S. M., Mechanical Properties Study of Pseudo-Stem Banana Fiber Reinforced Epoxy Composite, The Arabian Journal for Science and Engineering, 32 (2007), pp. 359-364.

[13].Wijianto ,Rijal Muhamad Diar Ibnu,Hepy Adityarini ,Effect of NaOH Concentration Treatment on Tensile Strength, Flexure Strength and Elasticity Modulus of Banana Fiber Reinforced Polyester Resin. 
Swaroop. et.al / REST Journal on Emerging trends in Modelling and Manufacturing 6(2) 2020, 40-44

[14].Jenarthanan, M. P., and R. Jeyapaul. "Optimisation of machining parameters on milling of GFRP composites by desirability function analysis using Taguchi method." International journal of Engineering, science and Technology 5, no. 4 (2013): 22-36. 